\title{
The impact of albumin infusion on the risk of rebleeding and in-hospital mortality in cirrhotic patients admitted for acute gastrointestinal bleeding: a retrospective study of a single institute
}

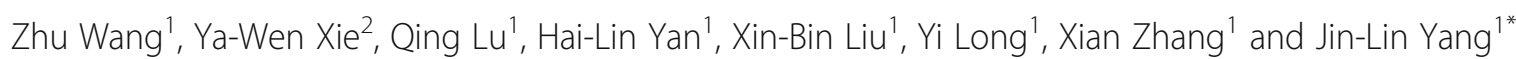

\begin{abstract}
Background: To investigate the effect of albumin infusion on cirrhotic patients admitted for acute gastrointestinal bleeding.

Methods: Medical records of cirrhotic patients who admitted due to acute gastrointestinal bleeding through January 2009 to December 2018 were reviewed. Clinical data and the total amount of albumin and red blood cell used during hospitalization were recorded. For patients with rebleeding, the amount of albumin and red blood cell used before rebleeding was also documented. The primary outcome was the occurrence of rebleeding, and the second outcome was in-hospital mortality. Univariate and multivariate logistic analysis was performed to identify risk factors associated with rebleeding and in-hospital mortality.

Results: A total of 1503 cirrhotic patients were included in the analysis. There were 146 episodes of in-patient rebleeding occurred, while 81 patients died. Overall, more red blood cells and albumin were prescribed to patients who suffered rebleeding. In terms of the amount before rebleeding, the red blood cell was higher in patients with rebleeding, but the albumin infusion was similar. In the multivariate model, the albumin infusion before rebleeding was an independent risk factor associated with rebleeding (adjusted OR for $\leq 40 \mathrm{~g}$ vs 0 g, 0.469 [0.2690.793], $p=0.006$; adjusted OR for $>40 \mathrm{~g}$ vs $0 \mathrm{~g}, 0.272$ [0.115-0.576], $p=0.001$ ). In Child-Pugh C class patients, the use of albumin more than $40 \mathrm{~g}$ during hospitalization associated with a lower risk of in-patient mortality (adjusted OR for $>40 \mathrm{~g}$ vs $0 \mathrm{~g}, 0.136$ [0.019-0.741], $p=0.031$ ).
\end{abstract}

Conclusions: Albumin infusion was associated with a lower risk of rebleeding and in-hospital deaths in cirrhosis admitted for acute gastrointestinal bleeding.

Keywords: Albumin, Cirrhosis, Gastrointestinal bleeding, Portal hypertension

\footnotetext{
* Correspondence: mouse-577@163.com

'Department of Gastroenterology and Hepatology, West China Hospital of Sichuan University, 37\# Guoxue Lane, Chengdu 610041, Sichuan, China

Full list of author information is available at the end of the article
}

(c) The Author(s). 2020 Open Access This article is licensed under a Creative Commons Attribution 4.0 International License, which permits use, sharing, adaptation, distribution and reproduction in any medium or format, as long as you give appropriate credit to the original author(s) and the source, provide a link to the Creative Commons licence, and indicate if changes were made. The images or other third party material in this article are included in the article's Creative Commons licence, unless indicated otherwise in a credit line to the material. If material is not included in the article's Creative Commons licence and your intended use is not permitted by statutory regulation or exceeds the permitted use, you will need to obtain permission directly from the copyright holder. To view a copy of this licence, visit http://creativecommons.org/licenses/by/4.0/. The Creative Commons Public Domain Dedication waiver (http://creativecommons.org/publicdomain/zero/1.0/) applies to the data made available in this article, unless otherwise stated in a credit line to the data. 


\section{Background}

Gastrointestinal bleeding (GIB) accounts for nearly onethird of all death in cirrhotic patients. Hypoalbuminemia, frequently caused by the impaired synthesis in the scenario of advanced cirrhosis, may further deteriorate after GIB due to the direct loss of albumin in the gastrointestinal tract and short-term fast. As an established risk factor for sepsis and mortality in critically ill patients, hypoalbuminemia needs to be corrected by albumin treatment [1]. In patients with cirrhosis, the use of albumin prevents circulatory dysfunction after paracentesis, improves the outcomes in patients with refractory ascites, spontaneous bacterial peritonitis (SBP) and hepatorenal syndrome (HRS) [2, 3]. However, no studies thus far have elucidated its role in the management of GIB in cirrhotic patients.

The antibiotic prophylaxis has been accepted by international consensus for its role in reducing rebleeding risk in cirrhotic patients [4]. The therapeutic effect of antibiotics in cirrhosis is attributed to the improvement of the inflammatory state caused by bacterial infection [5]. Meanwhile, emerging evidence supports the antiinflammatory property of albumin, which contributes to reducing the risk of complications and mortality rate in cirrhotic patients $[6,7]$. On the contrary, albumin infusion, noted as a volume expander, may increase portal pressure and induce rebleeding due to deteriorated pre-existing portal hypertension [8]. Therefore, our study aims to investigate whether the albumin infusion would affect the prognosis of cirrhotic patients admitted for GIB.

\section{Methods}

\section{Study design}

Medical records of cirrhotic patients who admitted to West China Hospital due to GIB through Jan 2009 to Dec 2018 were systemically reviewed. Data of patients' demographics, cause of cirrhosis, Child-Pugh classification, laboratory tests, days of hospital stay, sources of bleeding, initial rescue therapy with balloon tamponade, endoscopic and radiological interventions, the concomitant of hepatic carcinoma (HCC) and portal vein thrombosis (PVT), the occurrence of in-hospital rebleeding and deaths were collected based on the medical records.

The sources of bleeding were defined as the upper or lower GI tract according to endoscopic findings. The upper GI bleeding was further divided into variceal and non-variceal bleeding lesions as determined by esophagogastroduodenoscopy. Variceal bleeding was defined as active hemorrhage from varices, or the presence of a clot over varices, or varices as the only potential source of bleeding. Patients with multiple suspected bleeding lesions were recorded respectively. The presence of HCC or PVT was confirmed by radiological imaging records or discharge diagnosis. The baseline values of hemoglobin, bilirubin, albumin, creatine, and prothrombin time were obtained from the laboratory results at admission. Patients with HCC or PVT were excluded from further analysis.

\section{Clinical outcomes}

The primary outcome was the in-hospital rebleeding event, defined as the following symptoms documented in the medical records that occurred after initial hemostasis achieved: 1) new occurrence of hematemesis or bloody nasogastric aspirate; 2) recurrence of hematochezia or melena. The secondary outcome was inhospital mortality. The death reasons were derived from the discharge diagnosis.

\section{Infusion of albumin and red blood cell}

The amount of albumin and red blood cell (RBC) infusion during hospitalization was collected from the hospital database. The total amount of albumin and RBC used during hospitalization were recorded as total-ALB and total-RBC. For patients with rebleeding occurred, the amount of albumin and $\mathrm{RBC}$ used before rebleeding was recorded as pre-ALB and pre-RBC. For patients without rebleeding, the amount of pre-ALB and pre$\mathrm{RBC}$ was equivalent to the total-ALB and total-RBC.

\section{Statistical analysis}

Continuous variables were displayed as means \pm standard deviation and compared using the Student's $t$ test. Categorical variables were displayed as frequencies and percentages and compared by Chi-square or Fisher exact tests. Baseline characteristics and other associated covariates with outcomes were estimated with univariate and multivariate logistic regression models and reported as odds ratios (OR) with $95 \%$ confidence intervals (CI). Statistics are calculated using $\mathrm{R}$ version 3.2.0 ( $\mathrm{R}$ Foundation for Statistical Computing, Vienna, Austria).

\section{Results}

\section{Patients' baseline characteristics and outcomes}

A total of 2259 records of cirrhotic patients admitted for acute GIB were selected, among whom 20 cases were excluded for the incomplete data. There were 736 patients with PVT or HCC were excluded. Overall, 1503 records were included in this study. The mean age was $53.1 \pm$ 13.1, 1005 (66.9\%) were male. Except for 190 (12.6\%) cases without identified etiology, the other etiologies for cirrhosis were: 867 (57.7\%) HBV infections; 197 (13.1\%) alcoholic liver diseases; 135 (9.0\%) autoimmune liver diseases; 59 (3.9\%) HCV infections; 22 (1.5\%) secondary cholestatic liver diseases; 10 (0.7\%) vascular disorders, 23 (1.5\%) others. According to the Child-Pugh classification, there were $474(31.5 \%)$ patients classified as class 
A, $715(47.6 \%)$ as class B, and $314(20.9 \%)$ as class C. At admission, 123 patients were concomitant with encephalopathy, and 750 patients had ascites. In terms of the rebleeding sources, there were $128(8.5 \%)$ patients who did not receive endoscopy examinations to identify the bleeding lesion (unidentified lesion). Because they could not tolerate interventions due to comorbidities or patients avoid endoscopic interventions. There were 1375 (91.5\%) cases presented upper GI tract bleeding lesion (variceal or non-variceal lesions) and 47 (3.1\%) had lower GI tract bleeding lesions (jejunoileal or colonic lesion). Variceal lesion were observed in 1275 cases (84.8\%), while non-variceal lesion in 100 patients (6.7\%). In variceal bleeding, balloon tamponade was initially applied in 169 cases to control active bleeding, 21 emergent transjugular intrahepatic portosystemic shunts (TIPS) were performed as rescue therapy. During hospitalization, 511 (34.0\%) patients received endoscopic treatments, including 491 cases of endoscopic band ligation with/without injection of tissue adhesive, 19 cases of endoscopic sclerotherapy/injection of tissue adhesive, 1 cases endoscopic treatment for ulcer lesions. About half of the endoscopic treatments (251, 49.1\%) were performed within 5 days to prevent early rebleeding. There were 10 cases underwent additional radiological interventional treatment due to the failure of endoscopic treatments, while $372(25.0 \%)$ patients only underwent radiological interventional treatment. The majority of the radiological interventions were TIPS $(352,92.1 \%)$ for the failure of previous endoscopic treatment prevention. The other interventions including balloon-occluded retrograde obliteration (20, 5.2\%), embolization of non-variceal lesion $(8,2.1 \%)$, and partial splenic embolization (2, 0.5\%).

Overall, there were 146 (9.7\%) patients for whom inpatient rebleeding occurred, with an average of $12.2 \pm$ 6.5 hospitalization days. As regards the in-hospital mortality, a total of 81 (5.4\%) patients died during hospitalization and 67 of them experienced in-patient rebleeding before death. The reasons of deaths were as followed: hemorrhagic shock $(n=57)$, hepatorenal syndrome $(n=11)$, hepatic encephalopathy $(n=1)$, multiple organ failure $(n=6)$, infection $(n=2)$, cerebrovascular event $(n=3)$, and acute myocardial infarction $(n=1)$.

\section{The association between albumin/RBC infusion for in- patient rebleeding}

Univariate variables associated with rebleeding were displayed in Table 1. Patients suffered rebleeding were more likely to have hepatic encephalopahty $(6.9 \%$ vs $19.9 \%, p<0.001$ ), higher Child-Pugh classification (Child A $33.5 \%$ vs $13.0 \%$, Child B $47.1 \%$ vs $52.1 \%$, Child C $19.4 \%$ vs $34.9 \%, p<0.001$ ), higher bilirubin level (32.5 vs 48.4 umol/L, $p<0.001)$, lower albumin level (31.0 vs
Table 1 Univariate analysis of baseline characteristics between patients with and without rebleeding

\begin{tabular}{|c|c|c|c|}
\hline & $\begin{array}{l}\text { No rebleeding } \\
(n=1357)\end{array}$ & $\begin{array}{l}\text { Rebleeding } \\
(n=146)\end{array}$ & $P$ value \\
\hline Age & $52.9 \pm 13.0$ & $54.6 \pm 13.3$ & 0.144 \\
\hline Gender (Male) & $907(66.8)$ & $98(67.1)$ & 1 \\
\hline Child-Pugh class & & & $<0.001$ \\
\hline A & $455(33.5)$ & $19(13.0)$ & \\
\hline B & $639(47.1)$ & $76(52.1)$ & \\
\hline C & $263(19.4)$ & $51(34.9)$ & \\
\hline Hepatic encephalopathy & $94(6.9)$ & $29(19.9)$ & $<0.001$ \\
\hline Ascites & $699(51.5)$ & $51(34.9)$ & $<0.001$ \\
\hline \multicolumn{4}{|l|}{ Source of Bleeding } \\
\hline Varices lesion & $1154(85.0)$ & $121(82.9)$ & 0.568 \\
\hline Non-varices lesion & $96(7.1)$ & $4(2.7)$ & 0.068 \\
\hline Lower gastrointestinal lesion & $43(3.2)$ & $4(2.7)$ & 0.974 \\
\hline Unidentified lesion & $108(8.0)$ & $20(13.7)$ & 0.027 \\
\hline Bilirubin (umol/L) ${ }^{a}$ & $32.5 \pm 40.6$ & $48.4 \pm 88.4$ & $<0.001$ \\
\hline Albumin $(\mathrm{g} / \mathrm{L})^{\mathrm{a}}$ & $31.0 \pm 6.1$ & $27.8 \pm 6.6$ & $<0.001$ \\
\hline Creatine $(\mathrm{mol} / \mathrm{L})^{a}$ & $80.6 \pm 60.3$ & $90.1 \pm 58.5$ & 0.071 \\
\hline Hemoglobin $(g / L)^{a}$ & $75.8 \pm 22.9$ & $73.7 \pm 22.3$ & 0.274 \\
\hline Prothrombin time $(\mathrm{s})^{a}$ & $16.6 \pm 9.7$ & $18.3 \pm 10.5$ & 0.038 \\
\hline Balloon tamponade & $95(7.0)$ & $74(50.7)$ & $<0.001$ \\
\hline Endoscopic treatment & $489(36.0)$ & $22(15.1)$ & $<0.001$ \\
\hline Radiological intervention & $336(24.8)$ & $46(31.5)$ & 0.093 \\
\hline
\end{tabular}

values were obtained at admission

$27.8 \mathrm{~g} / \mathrm{L}, p<0.001$ ), and deteriorated prothrombin time at baseline (16.6 vs $18.3 \mathrm{~s}, p=0.038)$. More rebleeding occurred in cases with unidentified lesions $(8.0 \%$ vs $13.7 \%, p=0.027)$ and patients without ascites $(51.5 \%$ vs $34.9 \%, p<0.001)$. Rebleeding was more likely to occur in patients rescued by balloon tamponade at admission (7.0\% vs $50.7 \%, p<0.001$ ), while subsequent endoscopic treatment effectively prevents rebleeding $(36.0 \%$ vs $15.1 \%, p<0.001$ ) (Table 1).

An average of $2.3 \pm 3.3$ units of RBC and $14.2 \pm 32.3 \mathrm{~g}$ albumin were administrated to patients presented anemia or hypoalbuminemia. During hospitalization, the average minimum value of HGB and albumin were significantly higher in those patients without rebleeding (Table 2). Hence, more total-RBC $(1.9 \pm 2.5$ vs $6.7 \pm 5.9$ units, $p<$ $0.001)$ and total-ALB $(12.7 \pm 28.7$ vs $28.5 \pm 53.3 \mathrm{~g}, p<$ 0.001 ) were prescribed to patients who had rebleeding, compared to those without rebleeding. Nevertheless, the pre-RBC transfusion was higher in rebleeding patients $(1.9 \pm 2.5$ vs $4.1 \pm 3.9$ units, $p<0.001)$, while the pre-ALB infusion was comparable $(12.7 \pm 28.7$ vs $10.5 \pm 34.4 \mathrm{~g}, p=$ 0.395). In particular, in patients with Child-Pugh $C$ class, the pre-ALB infusion was lower in those with rebleeding (14.1 vs $29.9 \mathrm{~g}, p=0.021$ ). (Table 2 ). 
Table 2 The amount of albumin and RBC infusion in cirrhosis with and without in-patient rebleeding

\begin{tabular}{|c|c|c|c|c|c|c|c|c|c|}
\hline & \multicolumn{3}{|l|}{ Child-Pugh A } & \multicolumn{3}{|l|}{ Child-Pugh B } & \multicolumn{3}{|l|}{ Child-Pugh C } \\
\hline & No rebleeding & rebleeding & $P$ value & No rebleeding & rebleeding & $P$ value & No rebleeding & rebleeding & $P$ value \\
\hline Albumin $(\mathrm{g} / \mathrm{L})^{\mathrm{b}}$ & 32.9 & 24.6 & $<0.001$ & 27.9 & 23 & $<0.001$ & 24.3 & 20.9 & 0.001 \\
\hline Total-ALB (g) ${ }^{a}$ & 3.0 & 18.3 & $<0.001$ & 12.5 & 30.3 & $<0.001$ & 29.9 & 29.7 & 0.974 \\
\hline Pre-ALB (g) ${ }^{c}$ & 3.0 & 2.2 & 0.790 & 12.5 & 10.2 & 0.462 & 29.9 & 14.1 & 0.021 \\
\hline $\mathrm{HGB}(\mathrm{g} / \mathrm{L})^{\mathrm{b}}$ & 71.9 & 57.2 & $<0.001$ & 65.6 & 52.6 & $<0.001$ & 61.7 & 55.2 & 0.041 \\
\hline Total-RBC (unit) ${ }^{a}$ & 1.2 & 6.0 & $<0.001$ & 2.0 & 7.5 & $<0.001$ & 2.5 & 5.8 & $<0.001$ \\
\hline Pre-RBC (unit) ${ }^{c}$ & 1.2 & 3.1 & $<0.001$ & 2.0 & 4.8 & $<0.001$ & 2.5 & 3.5 & 0.032 \\
\hline
\end{tabular}

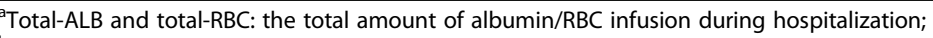

${ }^{\mathrm{b}}$ The average minimum value of albumin or hemoglobin during hospitalization;

'Pre-ALB and pre-RBC: the amount of albumin infusion before rebleeding occurrence. In patients without bleeding, the pre-ALB and pre-RBC equals the total-ALB and total-RBC

To explore the association between the dose and risk of rebleeding, the amount of pre-ALB was further classified into two subgroups as $\leq 40 \mathrm{~g}$ and $>40 \mathrm{~g}$. The use of pre-ALB was not linked to rebleeding in univariate analysis. In the multivariate model adjusted for baseline albumin and Child-Pugh class, however, the use of an increased dose of albumin reduces the risk of rebleeding (OR for $\leq 40 \mathrm{~g}$ vs $0 \mathrm{~g}, 0.500$ [0.312-0.800], $p=$ 0.004 ; OR for $>40 \mathrm{~g}$ vs $0 \mathrm{~g}$, OR 0.279 [0.134-0.580], $p<0.001)$.(Table 3).

Furthermore, in another multivariate model adjusted for all confounders (Child-Pugh class, presence of hepatic encephalopathy and ascites, bleed from unidentified lesion, the initial application of balloon tamponade, values of bilirubin, albumin and prothrombin time, endoscopic treatments), the pre-ALB infusion was still associated with a lower risk of rebleeding. There was a negative dose-effect relationship between albumin and rebleeding risk (adjusted OR for $\leq 40 \mathrm{~g}$ vs $0 \mathrm{~g}, 0.469$ [0.269-0.793], $p=0.006$; adjusted OR for $>40 \mathrm{~g}$ vs $0 \mathrm{~g}$, $0.272[0.115-0.576], p=0.001)$. Other independent factors in this model included Child-Pugh classification (adjusted OR for Child B vs A, 1.935 [1.090-3.563], $p=$
0.028; Child C vs A, 2.253 [1.094-4.730], $p=0.029$ ), presence of encephalopathy (adjusted OR 1.951 [1.0293.621], $p=0.037$ ) and ascites (adjusted OR 0.526 [0.3440.799 ], $p=0.003$ ), rescue therapy with balloon tamponade (adjusted OR 13.996 [9.002-21.882], $p<0.001$ ) and endoscopic treatment (adjusted OR 0.337 [0.195-0.561], $p<0.001$ ) (Fig. 1a).

Regarding $\mathrm{RBC}$ infusion before rebleeding, the pre$\mathrm{RBC}$ infusion remained associated with more occurrences of rebleeding in univariate (OR for $4-8$ vs $<4$ units 3.556 [2.369-5.338], $p<0.001$; OR for $>8$ vs $<4$ units 5.654 [2.913-10.975], $p<0.001)$. In the multivariate analysis adjusted for the confounders above, the risk was positively correlated with the infused RBC units (adjusted OR for $4-8$ vs $<4$ units 1.888 [1.144-3.067], $p=$ 0.011 ; adjusted OR for $>8$ vs $<4$ units 2.634 [1.1425.812], $p=0.019$ ) (Fig. 1b).

When the multivariate analysis were further performed stratified by Child-Pugh class, the benefit effect of preALB infusion was only observed in patients of ChildPugh C class (adjusted OR for $\leq 40 \mathrm{~g}$ vs $0 \mathrm{~g}, 0.185$ [0.057-0.520], $p=0.002$; adjusted OR for $>40 \mathrm{~g}$ vs $0 \mathrm{~g}$, $0.198[0.047-0.668], p=0.015)$. While, the negative

Table 3 Multivariate Hazards regression analysis of the relationship between different dose of albumin/red blood cell infusion before rebleeding and rebleeding

\begin{tabular}{|c|c|c|c|c|}
\hline \multicolumn{5}{|l|}{ Pre-ALB infusion } \\
\hline & $(0,40 \mathrm{~g}]$ & $P$ value & $>40 \mathrm{~g}$ & $P$ value \\
\hline Unadjusted & $0.879(0.561-1.376)$ & 0.572 & $0.575(0.285-1.160)$ & 0.122 \\
\hline Adjusted for albumin, Child-Pugh class & $0.500(0.312-0.800)$ & 0.004 & $0.279(0.134-0.580)$ & $<0.001$ \\
\hline Multivariable adjusted & $0.469(0.269-0.793)$ & 0.006 & $0.272(0.115-0.576)$ & 0.001 \\
\hline \multicolumn{5}{|l|}{ Pre-RBC infusion } \\
\hline & (4-8 units] & $P$ value & $>8$ units & $P$ value \\
\hline Unadjusted & $3.556(2.369-5.338)$ & $<0.001$ & $5.654(2.913-10.975)$ & $<0.001$ \\
\hline $\begin{array}{l}\text { Adjusted for hemoglobin, } \\
\text { Child-Pugh class }\end{array}$ & $3.497(2.229-5.485)$ & $<0.001$ & $5.709(2.852-11.426)$ & $<0.001$ \\
\hline Multivariable ${ }^{a}$ adjusted & $1.888(1.144-3.067)$ & 0.011 & $2.634(1.142-5.812)$ & 0.019 \\
\hline
\end{tabular}

adjust for Child-Pugh classification, presence of encephalopathy and ascties, bleed from unidentified lesion, the initial application of tamponade, values of bilirubin, albumin and prothrombin time, endoscopic treatments 


$\begin{array}{lcc}\text { a } & & \text { Odd ratio }(95 \% \mathrm{Cl}, \mathrm{p}) \\ \text { Pre-albumin infusion } & 0 & - \\ & (0,40] & 0.47(0.27-0.79,0.006) \\ & >40 & 0.27(0.12-0.58,0.001) \\ \text { Child-Pugh class } & \mathrm{A} & - \\ & \mathrm{B} & 1.94(1.09-3.56,0.028) \\ & \mathrm{C} & 2.25(1.09-4.73,0.029) \\ \text { Unidentified lesion } & \text { no } & - \\ \text { Bilirubin } & \text { yes } & 1.81(0.97-3.26,0.052) \\ \text { Albumin } & \text { mean(SD) } & 1.00(1.00-1.00,0.337) \\ \text { Prothrombin time } & \text { mean(SD) } & 0.95(0.91-0.98,0.003) \\ & \text { mean(SD) } & 1.00(0.97-1.01,0.640) \\ \text { Balloon tamponade } & \text { no } & - \\ & \text { yes } & 13.97(9.00-21.88,<0.001) \\ \text { Endoscopic treatments } & \text { no } & - \\ \text { yes } & 0.34(0.19-0.56,<0.001) \\ \text { Hepatic encephalopathy } & \text { no } & - \\ \text { yes } & 1.95(1.03-3.62,0.037) \\ \text { Ascites } & \text { no } & - \\ & \text { yes } & 0.53(0.34-0.80,0.003)\end{array}$

\section{b}

$\begin{array}{lcc} & {[0,4]} & - \\ \text { Pre-RBC infusion } & (4,8] & 1.89(1.14-3.07,0.011) \\ & >8 & 2.63(1.14-5.81,0.019) \\ \text { Child-Pugh class } & \text { A } & - \\ & \text { B } & 1.75(0.98-3.24,0.067) \\ & \text { C } & 1.85(0.90-3.91,0.100) \\ \text { Unidentified lesion } & \text { no } & - \\ \text { Bilirubin } & \text { yes } & 1.71(0.92-3.06,0.078) \\ \text { Albumin } & \text { mean (SD) } & 1.00(1.00-1.01,0.207) \\ \text { Prothrombin time } & \text { mean (SD) } & 0.97(0.93-1.00,0.083) \\ \text { Balloon tamponade } & \text { mean (SD) } & 0.99(0.97-1.01,0.507) \\ & \text { no } & - \\ \text { Endoscopic treatment } & \text { yes } & 11.18(7.22-17.44,<0.001) \\ \text { Hepatic encephalopathy } & \text { yes } & -0.32(0.18-0.54,<0.001) \\ & \text { no } & - \\ \text { Ascites } & \text { yes } & 1.87(1.01-3.36,0.042) \\ & \text { no } & - \\ & \text { yes } & 0.44(0.29-0.67,<0.001)\end{array}$
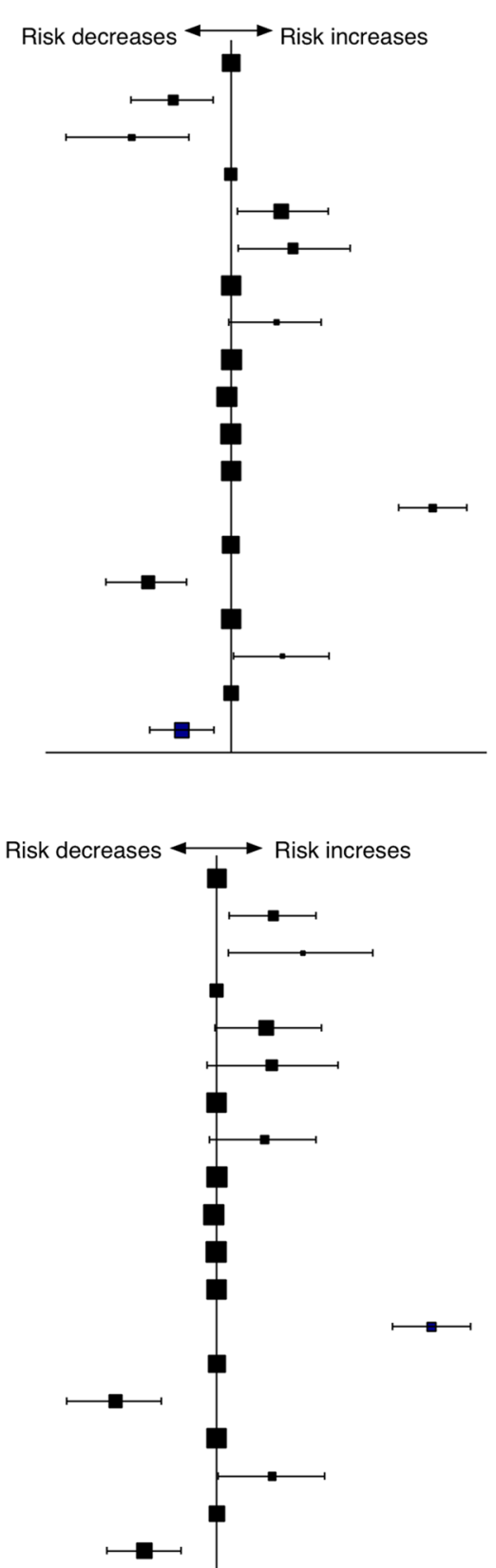

Fig. 1 Multivariate hazard regression of (a) different dose (g) of albumin infusion before rebleeding (pre-ALB); (b) different dose (units) of red blood cell infusion (pre-RBC) and rebleeding event

impact of pre-RBC infusion was predominantly shown in patients of Child-Pugh B class (adjusted OR for 48 vs $<4$ units 2.235 [1.168-4.180], $p=0.013$; adjusted OR for $>8$ vs $<4$ units 3.495 [1.254-9.373], $p=0.014)$.

The association between albumin/RBC infusion and inhospital mortality

In the univariate analysis, the in-hospital mortality was more probable in patients with compromised liver function (i.e. higher Child-Pugh classification, lower values of albumin, higher values of bilirubin, creatine and prothrombin time), prensece of encephalopathy, bleed from varices or unidentified lesion, initial rescue therapy with tamponade and occurrence of rebleeding. The presence of ascites, the uses of endoscopic and radiological interventions decreased mortality risk (Table 4). A higher amount of total-RBC $(2.2 \pm 3.1$ vs $5.5 \pm 5.3$ units, $p<0.001)$ and similary amount of total-ALB $(13.9 \pm 31.0$ $\mathrm{g}$ vs $19.8 \pm 49.1 \mathrm{~g}, p=0.114)$ infused to patients who died during hospitalization. However, after adjusted for 
Table 4 Univariate analysis of baseline characteristics and mortality

\begin{tabular}{|c|c|c|c|}
\hline & $\begin{array}{l}\text { No death } \\
(n=1422)\end{array}$ & $\begin{array}{l}\text { Death } \\
(n=81)\end{array}$ & $P$ value \\
\hline Age & $53.0 \pm 13.0$ & $54.2 \pm 13.5$ & 0.444 \\
\hline Gender (M) & 947 (66.6) & $58(71.6)$ & 0.418 \\
\hline Child-Pugh classification & & & $<0.001$ \\
\hline A & $469(33.0)$ & $5(6.2)$ & \\
\hline B & $689(48.5)$ & $26(32.1)$ & \\
\hline C & $264(18.6)$ & $50(61.7)$ & \\
\hline Hepatic encephalopathy & $94(6.6)$ & $29(35.8)$ & $<0.001$ \\
\hline Ascites & 738 (51.9) & $12(14.8)$ & $<0.001$ \\
\hline Rebleeding & $79(5.6)$ & $67(82.7)$ & $<0.001$ \\
\hline \multicolumn{4}{|l|}{ Sources of bleeding } \\
\hline Varies lesion & $1215(85.4)$ & $60(74.1)$ & 0.009 \\
\hline Non-varices lesion & $99(7.0)$ & $1(1.2)$ & 0.075 \\
\hline Lower gastrointestinal lesion & $45(3.2)$ & $2(2.5)$ & 0.983 \\
\hline Unidentified lesion & $109(7.7)$ & $19(23.5)$ & $<0.001$ \\
\hline Bilirubin (umol /L) ${ }^{a}$ & $31.8 \pm 39.0$ & $74.1 \pm 116.7$ & $<0.001$ \\
\hline Albumin $(g / L)^{a}$ & $30.9 \pm 6.1$ & $26.6 \pm 6.5$ & $<0.001$ \\
\hline Creatine $(\mathrm{mol} / \mathrm{L})^{\mathrm{a}}$ & $79.7 \pm 58.4$ & $114.0 \pm 80.0$ & $<0.001$ \\
\hline Hemoglobin $(g / L)^{a}$ & $75.7 \pm 22.8$ & $74.6 \pm 24.0$ & 0.683 \\
\hline Prothrombin time $(\mathrm{s})^{\text {a }}$ & $16.5 \pm 9.5$ & $21.0 \pm 13.4$ & $<0.001$ \\
\hline Balloon tamponade & $133(9.4)$ & $36(44.4)$ & $<0.001$ \\
\hline Endoscopic treatment & $507(35.7)$ & $4(4.9)$ & $<0.001$ \\
\hline Radiological intervention & 381 (26.8) & $1(1.2)$ & $<0.001$ \\
\hline
\end{tabular}

${ }^{a}$ values were obtained at admission

baseline albumin level and Child-Pugh class, there was a significant correlation between total-ALB infusion and mortality (OR for $\leq 40 \mathrm{~g}$ vs $0 \mathrm{~g}, 0.485$ [0.265-0.888], $\mathrm{p}=$ 0.019; OR for > $40 \mathrm{~g}$ vs $0 \mathrm{~g}, 0.432$ [0.206-0.903], $\mathrm{p}=0.026$ ). In another multivariate model adjusted for all confounders (Child-Pugh classification, presence of encephalopathy and ascites, the occurrence of rebleeding, bleed from variceal lesion or unidentified lesion, the initial therapy of tamponade, values of bilirubin, creatine, albumin and prothrombin time, endoscopic and radiological interventions), the infusion of albumin does not correlated with inhospital mortality. (Table 5 and Fig. 2a).

On the other hand, the infusion of total-RBC increased the mortality risk in the univariate analysis (OR for 4-8 vs $<4$ units, 2.583 [1.448-4.608, $p=0.001$; OR for $>8$ vs $<4$ units, 8.350 [4.550-15.325], $p<0.001)$ and a multivariate model adjusted for baseline hemoglobin level and Child-Pugh class (OR for 4-8 vs <4 units, 2.373 [1.2534.493], $p=0.008$; OR for $>8$ vs $<4$ units, 8.399 [4.25616.577], $p<0.001)$. However, this association between $\mathrm{RBC}$ use and in-hospital mortality risk was not observed in another multivariate model adjusted for all confounders described above (adjusted OR for 4-8 vs <4 units, 1.198 [0.401-3.418], $p=0.740$; adjusted OR for $>8$ vs $<4$ units, 1.526 [0.422-5.608], $p=0.519$ ) (Fig. 2b).

Similarly, the multivariate analysis was performed in each Child-Pugh Class, the beneficial effect of total-ALB infusion was only observed in patients of $\mathrm{C}$ class (adjusted OR for $\leq 40 \mathrm{~g}$ vs $0 \mathrm{~g}, 0.653$ [0.111-3.404], $p=$ 0.618 ; adjusted OR for $>40 \mathrm{~g}$ vs $0 \mathrm{~g}, 0.136$ [0.019-0.741], $p=0.031$ ). Meanwhile, the total-RBC infusion was still not correlated with in-hospital mortality.

\section{Discussion}

Gastrointestinal bleeding (GIB) is a fatal complication of cirrhosis, especially for those with rupture of varices. The application of endoscopic and radiological interventions has greatly improved the prognosis of patients with acute GIB [9]. In addition to the advances of invasive treatments, the conservative treatments remain an integral part of the management of this medical emergency and are increasingly standardized. The therapeutic value of prophylactic antibiotics and restrict blood transfusion strategy has recently been proved by several clinical studies [5, 8]. However, the role of albumin in the

Table 5 Multivariate Hazards regression analysis of different dose of albumin/red blood cell and death

\begin{tabular}{|c|c|c|c|c|}
\hline \multicolumn{5}{|l|}{ Total-ALB infusion } \\
\hline & $(0,40 \mathrm{~g}]$ & $P$ value & $>40 \mathrm{~g}$ & $P$ value \\
\hline Unadjusted & $1.068(0.602-1.894)$ & 0.822 & 1.160 (0.579-2.323) & 0.676 \\
\hline Adjusted for albumin, Child-Pugh class & $0.485(0.265-0.888)$ & 0.019 & $0.432(0.206-0.903)$ & 0.026 \\
\hline Multivariable a adjusted & $0.892(0.299-2.522)$ & 0.833 & $0.403(0.117-1.268)$ & 0.133 \\
\hline \multicolumn{5}{|l|}{ Total-RBC infusion } \\
\hline & $(4,8$ units $]$ & $P$ value & $>8$ units & $P$ value \\
\hline Unadjusted & $2.583(1.448-4.608)$ & 0.001 & $8.350(4.550-15.325)$ & $<0.001$ \\
\hline $\begin{array}{l}\text { Adjusted for hemoglobin, } \\
\text { Child-Pugh class }\end{array}$ & $2.373(1.253-4.493)$ & 0.008 & $8.399(4.256-16.577)$ & $<0.001$ \\
\hline Multivariable adjusted & $1.198(0.401-3.418)$ & 0.740 & $1.526(0.422-5.608)$ & 0.519 \\
\hline
\end{tabular}

adjust for Child-Pugh classification, presence of encephalopathy and ascites, occurrence of rebleeding, bleed from varices lesion and unidentified lesion, the initial application of tamponade, values of bilirubin, creatine, albumin and prothrombin time, endoscopic and radiological treatment 


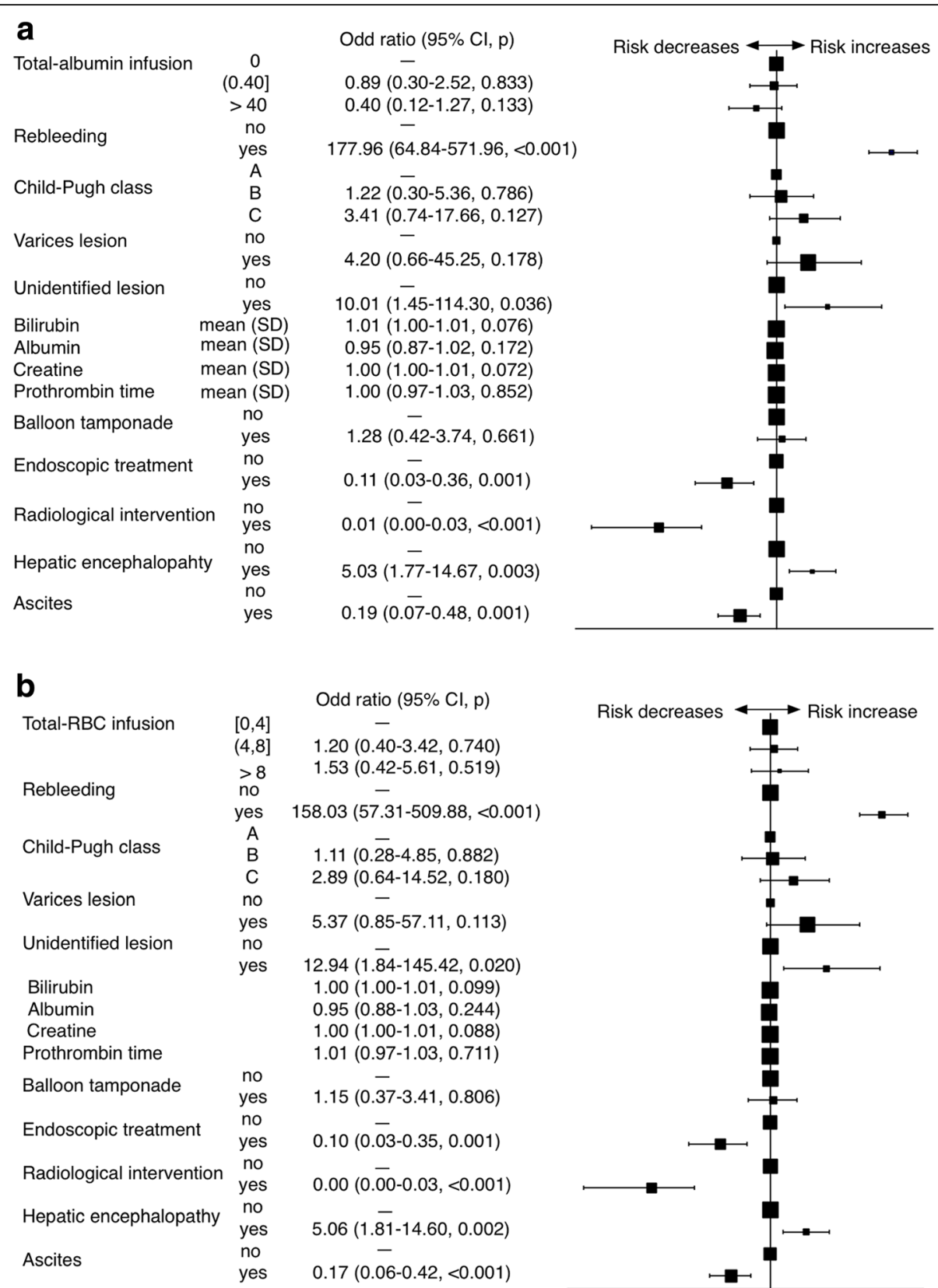

Fig. 2 Multivariate hazard regression of (a) different dose ( $\mathrm{g}$ ) of albumin infusion before rebleeding (total-ALB); (b) different dose (units) of red blood cell (total-RBC) infusion and mortality

management of GIB in patients with decompensated cirrhosis has not yet been assessed. This study demonstrated that albumin infusion was associated with a lower risk of rebleeding and in-hospital mortality.

Our study revealed a rebleeding rate of $9.7 \%$ and overall mortality of $5.4 \%$, which were lower than those described in previous studies possibly due to a shorter follow-up period in our study $[10,11]$. Despite the risk factors that are already known for rebleeding, our study found that the unidentified lesion also increased the risk of rebleeding and in-hospital mortality in cirrhotic patients $[5,11]$. UK consensus recommended endoscopic interventions to unstable patients with severe acute upper GIB immediately after resuscitation, and to all upper GIB patients within 24 h [12]. However, there was no recommendation about the time interval between bleeding and endoscopic treatment in the 2008 Chinese consensus, for not every hospital had the technical expertise required for these treatments [13]. In the past, treatments for variceal bleeding were usually delivered 
after hemodynamic hemostasis in our institute. Nevertheless, we tried to offer appropriate endoscopic therapies for variceal lesion within 5 days as to prevent early rebleeding. In recent years, we make efforts to provide timely endoscopic interventions as suggested to improve the prognosis [14].

Our study aims to explore whether albumin infusion influences the outcomes of cirrhotic patients admitted for GIB. Theoretically, abundant albumin infusion in patients with GIB may cause rebleeding by increased portal pressure in a similar manner of liberal transfusion strategy [15]. Interestingly, we found that albumin infusion associated with a lower risk of in-hospital rebleeding. Particularly, this beneficial effect was predominately observed in patients with Child-Pugh $\mathrm{C}$ class, who had a higher portal pressure. Also, the dosedependent effect of albumin in reducing rebleeding does not support the view that a higher dose leads to more bleeding events. In fact, a recent study suggests that the portal pressure was not affected after the infusion of albumin $(1.5 \mathrm{~g} / \mathrm{kg}$, every week) [6]. Hence, the concern that albumin infusion increases the risk of rebleeding due to deterioration of portal pressure seems unnecessary. On the other hand, albumin is used in cirrhosis for the treatment of SBP and was widely discussed in the sepsis treatment for its immunomodulatory and anti-inflammatory properties [16, 17]. As bacterial infection was identified as a critical determinant of rebleeding in cirrhosis by increasing portal pressure through vasoactive substances [5], the effect of albumin on systemic inflammation provides a potential theoretical basis for its role in reducing bleeding. Moreover, albumin may also control the bleeding risk by promoting the transportation of drugs such as proton pump inhibitor and antibiotics, two essential agents in the management of acute GIB. Indeed, a recent clinical study found that the combination of albumin and antibiotics is superior to antibiotics alone in the control of inflammation [6]. Collectively, the mechanisms involved the benefit of albumin is attributed to its effect on systemic inflammation and pharmacokinetic process, although its other properties may also play a role $[18,19]$.

The association between albumin infusion and inhospital mortality was also evaluated. Infection, HRS, and liver failure are the main non-bleeding cause of death in cirrhotic patients with acute GIB [10]. It is reasonable to assume that albumin treatment might ameliorate the number of deaths caused by infection or infection-related organ failures. Although the results showed that more than $40 \mathrm{~g}$ of albumin infusion lower risk of mortality in Child $C$ class, we failed to demonstrate the beneficial results of its effect on non-bleeding deaths since most patients dead from hemorrhagic shock. However, based on current evidence supporting its efficacy in these complications, we believe that the infusion of albumin for cirrhosis with GIB is favorable to improve the in-hospital prognosis in those with high-risk for non-bleeding death [16].

In this study, the pre-RBC infusion was positively correlated with the occurrence of rebleeding. It is not surprising that patients with rebleeding present severe bleeding at admission, thus require more RBC transfusion. Although the causal relationship between pre-RBC infusion and rebleeding cannot be determined based on current data, this issue has already been described by many well-designed studies $[8,20,21]$. The limited RBC transfusion reduces the occurrence of rebleeding, the survival benefit was not observed in our study. Its effect on survival was not inconsistent in previous reports probably due to the different enrollment criteria $[8,21-24]$. Nevertheless, the restrictive RBC transfusion is a cost-effective strategy as most studies show that less RBC transfusion does not correlate with poor prognosis. Similarly, the casual relationship between pre-ALB and rebleeding illustrated in this study needs to be valided by prospective research.

As a retrospective study, the limitations were inevitable. First, the time of albumin infusion before rebleeding was not evaluated. Normally, the albumin is not recommended in the initial resuscitation of hemorrhagic shock. Whether albumin should be applied in the resuscitation stage or after hemostasis achieved needs to be explored. Second, the average mimum albumin value and dose of albumin used in our study were low compared with previous study [16]. It resulted from the conventional view of albumin effect on GIB, as well as its high cost. Therefore, the necessarity of albumin infusion in patients without hypoproteinemia and the related dosage remains to be clarified. Thirdly, the 12-day follow-up period was shorter than those described in prior studies. As the rebleeding usually occurs within the first 2 weeks, we believe our analysis was still persuasive for the evaluation of the rebleeding event [8]. As its effect on survival, a longer follow-up is required. Lastly, apart from the variables we have included in the analysis, another important confounder is the difference of patient preference in the treatment decision. For example, those patients could afford more albumin were likely to accept endoscopic and radiological interventions. However, the effect of albumin infusion in cirrhosis with GIB has not been systemically studied. Our study would provide a reference for future studies in this subject. In summary, it is speculated that patients of $C$ class would benefit from albumin infusion. Details regarding the previous use of albumin, treatment regimen also needs to be considered in the future study with a longer followup period. 


\section{Conclusions}

The present study provides the first evidence supporting the application of albumin in the management of cirrhotic patients admitted for acute GIB. Albumin infusion was associated with a lower risk of in-hospital rebleeding in pateints with hypoalbuminemia, Moreover, in ChildPugh C class, albumin transfusion might be correlated with a decreased number of in-hospital deaths.

\section{Abbreviations}

GIB: Gastrointestinal bleeding; SBP: Spontaneous bacterial peritonitis; HRS: Hepatorenal syndrome; HCC: Hepatocellular carcinoma; PVT: Portal vein thrombosis; RBC: Red blood cell; ALB: Albumin

\section{Acknowledgments}

Not applicable.

\section{Authors' contributions}

WZ writing the manuscrtpt. WZ and YJL designed the research. XYW, LQ, YHL and LXB collected the research data. LY and ZX analyzed the data. All of the authors have read and approved the final manuscript.

\section{Funding}

The study design, data collection, analysis and interpretation of data, writing manuscript were funded by Key project of Sichuan Science and Technology Department (No. 2017FZ0091)

\section{Availability of data and materials}

The datasets used and/or analyzed during the current study are available from the corresponding author on reasonable request.

\section{Ethics approval and consent to participate}

This research protocol was approved by the Ethics Committee of the West China Hospital of Sichuan University.

\section{Consent for publication}

Not applicable.

\section{Competing interests}

All authors declare no conflicts of interest.

\section{Author details}

'Department of Gastroenterology and Hepatology, West China Hospital of Sichuan University, 37\# Guoxue Lane, Chengdu 610041, Sichuan, China.

${ }^{2}$ West China School of Medicine of Sichuan University, Chengdu, China.

Received: 24 December 2019 Accepted: 8 June 2020

Published online: 23 June 2020

\section{References}

1. Xu JY, Chen QH, Xie JF, Pan C, Liu SQ, Huang LW, Yang CS, Liu L, Huang YZ, Guo FM, et al. Comparison of the effects of albumin and crystalloid on mortality in adult patients with severe sepsis and septic shock: a metaanalysis of randomized clinical trials. Crit Care. 2014;18(6):702.

2. Garcia-Martinez R, Caraceni P, Bernardi M, Gines P, Arroyo V, Jalan R. Albumin: pathophysiologic basis of its role in the treatment of cirrhosis and its complications. Hepatology. 2013:58(5):1836-46.

3. Guevara M, Terra C, Nazar A, Sola E, Fernandez J, Pavesi M, Arroyo V, Gines P. Albumin for bacterial infections other than spontaneous bacterial peritonitis in cirrhosis. A randomized, controlled study. J Hepatol. 2012;57(4): 759-65.

4. de Franchis R, Baveno VF. Revising consensus in portal hypertension: report of the Baveno $\mathrm{V}$ consensus workshop on methodology of diagnosis and therapy in portal hypertension. J Hepatol. 2010;53(4):762-8.

5. Hou MC, Lin HC, Liu TT, Kuo Bl, Lee FY, Chang FY, Lee SD. Antibiotic prophylaxis after endoscopic therapy prevents rebleeding in acute variceal hemorrhage: a randomized trial. Hepatology. 2004;39(3):746-53.

6. Fernandez J, Claria J, Amoros A, Aguilar F, Castro M, Casulleras M, Acevedo J, Duran-Guell M, Nunez L, Costa M, et al. Effects of albumin treatment on systemic and Portal hemodynamics and systemic inflammation in patients with decompensated cirrhosis. Gastroenterology. 2019:157(1):149-62.

7. Thevenot T, Bureau C, Oberti F, Anty R, Louvet A, Plessier A, Rudler M, Heurgue-Berlot A, Rosa I, Talbodec N, et al. Effect of albumin in cirrhotic patients with infection other than spontaneous bacterial peritonitis. A randomized trial. J Hepatol. 2015;62(4):822-30.

8. Villanueva C, Colomo A, Bosch A, Concepcion M, Hernandez-Gea V, Aracil C, Graupera I, Poca M, Alvarez-Urturi C, Gordillo J, et al. Transfusion strategies for acute upper gastrointestinal bleeding. N Engl J Med. 2013;368(1):11-21.

9. Nevens F, Bittencourt PL, Coenraad MJ, Ding H, Hou MC, Laterre PF, Mendizabal M, Ortiz-Olvera NX, Vorobioff JD, Zhang W, et al. Recommendations on the diagnosis and initial Management of Acute Variceal Bleeding and Hepatorenal Syndrome in patients with cirrhosis. Dig Dis Sci. 2019;64(6):1419-31.

10. D'Amico G, De Franchis R, Cooperative Study G. Upper digestive bleeding in cirrhosis. Post-therapeutic outcome and prognostic indicators. Hepatology. 2003;38(3):599-612.

11. Garcia-Pagan JC, Reverter E, Abraldes JG, Bosch J. Acute variceal bleeding. Semin Respir Crit Care Med. 2012;33(1):46-54.

12. Tripathi D, Stanley AJ, Hayes PC, Patch D, Millson C, Mehrzad H, Austin A, Ferguson JW, Olliff SP, Hudson M, et al. U.K. guidelines on the management of variceal haemorrhage in cirrhotic patients. Gut. 2015;64(11):1680-704.

13. Cheng LF, Jia JD, Xu XY, Linghu EQ, Liu YL, Leng XS, Wang MQ. Task force for the $P$, management of esophagogastric variceal bleeding of the chinese society of G, Chinese society of $\mathrm{H}$ et al: Esophagogastric variceal bleeding in cirrhotic portal hypertension: consensus on prevention and management (2008). Chin Med J. 2009;122(7):766-75.

14. Brunner F, Berzigotti A, Bosch J. Prevention and treatment of variceal haemorrhage in 2017. Liver Int. 2017;37(Suppl 1):104-15.

15. China L, Skene SS, Shabir Z, Maini A, Sylvestre Y, Bennett K, Bevan S, O'Beirne J, Forrest E, Portal J, et al. Administration of Albumin Solution Increases Serum Levels of albumin in patients with chronic liver failure in a single-arm feasibility trial. Clin Gastroenterol Hepatol. 2018;16(5):748-55 e746.

16. Salerno F, Navickis RJ, Wilkes MM. Albumin infusion improves outcomes of patients with spontaneous bacterial peritonitis: a meta-analysis of randomized trials. Clin Gastroenterol Hepatol. 2013;11(2):123-30 e121.

17. Artigas A, Wernerman J, Arroyo V, Vincent J-L, Levy M. Role of albumin in diseases associated with severe systemic inflammation: pathophysiologic and clinical evidence in sepsis and in decompensated cirrhosis. J Crit Care. 2016:33:62-70

18. Cheng HC, Chang WL, Chen WY, Tsai YC, Yeh YC, Sheu BS. Intravenous albumin shortens the duration of hospitalization for patients with hypoalbuminemia and bleeding peptic ulcers: a pilot study. Dig Dis Sci. 2013:58(11):3232-41.

19. Matsuda S, Niihara M, Tsubosa Y, Sato H, Takebayashi K, Kawamorita K, Mori K, Tsushima T, Yasui $H$, Takeuchi $H$, et al. Clinical significance of postoperative recovery of serum albumin levels in patients with esophageal cancer who underwent transthoracic esophagectomy. Surg Today. 2016;46(10):1138-45.

20. Sung JJ, Chiu PW, Chan FKL, Lau JY, Goh KL, Ho LH, Jung HY, Sollano JD, Gotoda $\mathrm{T}$, Reddy $\mathrm{N}$, et al. Asia-Pacific working group consensus on non-variceal upper gastrointestinal bleeding: an update 2018. Gut. 2018;67(10):1757-68.

21. Chen YC, Hsiao CT, Lin LC, Hsiao KY, Hung MS. The association between red blood cell transfusion and outcomes in patients with upper gastrointestinal bleeding. Clin Transl Gastroenterol. 2018;9(3):138.

22. Mirski MA, Frank SM, Kor DJ, Vincent JL, Holmes DR, Jr. Restrictive and liberal red cell transfusion strategies in adult patients: reconciling clinical data with best practice. Crit Care. 2015:19(1):202.

23. Odutayo A, Desborough MJR, Trivella M, Stanley AJ, Dorée C, Collins GS, Hopewell S, Brunskill SJ, Kahan BC, Logan RFA, et al. Restrictive versus liberal blood transfusion for gastrointestinal bleeding: a systematic review and meta-analysis of randomised controlled trials. Lancet Gastroenterol Hepatol. 2017:2(5):354-60.

24. Jairath V, Kahan BC, Gray A, Doré CJ, Mora A, James MW, Stanley AJ, Everett SM, Bailey AA, Dallal $H$, et al. Restrictive versus liberal blood transfusion for acute upper gastrointestinal bleeding (TRIGGER): a pragmatic, open-label, cluster randomised feasibility trial. Lancet. 2015:386(9989):137-44.

\section{Publisher's Note}

Springer Nature remains neutral with regard to jurisdictional claims in published maps and institutional affiliations. 